\title{
Marcuse: cultura, ideologia e emancipação no capitalismo tardio
}

\section{Marcuse: culture, ideology and emancipation in late capitalism}

\section{Luiz Antonio da Silva Peixoto*}

Universidade Federal de Juiz de Fora - UFJF, Juiz de Fora, MG, Brasil

\begin{abstract}
RESUMO
Este artigo tematiza os elementos fundamentais da teoria crítica da sociedade de Herbert Marcuse no que se refere aos campos da crítica da cultura e da crítica da ideologia, discutindo especialmente as formas de dominação e de subjetividade prevalecentes no capitalismo tardio; bem como as possibilidades objetivas de transformação histórica no sentido da emancipação social. O pressuposto adotado é de que a atualização das análises marcuseanas da cultura afirmativa idealista, da dessublimação repressiva da cultura e da fusão entre ideologia e realidade econômica e social nos permite compreender as novas formas de subjetividade contemporâneas e explorar os mecanismos ideológicos de dominação nas sociedades pós-modernas, contribuindo para a fundamentação de uma teoria social crítica do capitalismo em sua fase neoliberal ou globalizada.
\end{abstract}

Palavras-chave: Cultura afirmativa, Crítica da ideologia, Emancipação social, Capitalismo tardio.

\begin{abstract}
This article studies the fundamentals of critical theory of society of Herbert Marcuse in relation to the fields of cultural criticism and the critique of ideology, especially discussing the forms of domination and subjectivity prevalent in late capitalism, and the objective possibilities historical transformation towards social emancipation. The assumption adopted is that the update of Marcuse analyzes affirmative and idealistic culture, the desublimation repressive of culture and fusion of ideology and economic and social reality allows us to understand the new forms of contemporary subjectivity and explore the mechanisms of ideological domination in post modernists societies, contributing to the reasons for a critical social theory of capitalism in its neoliberal phase or global.
\end{abstract}

Keywords: Affirmative culture, Critique of ideology, Social emancipation, Late capitalism.

Marcuse caracteriza o capitalismo norte-americano - tomado como modelo do capitalismo tardio - como o caminho para o que denomina de sociedade unidimensional (1982, p. 18): uma sociedade que controla e integra todas as dimensões da existência privada e pública, que assimila forças e interesses antes opostos, que administra metodicamente os instintos humanos; uma sociedade na qual toda força de negação está reprimida e se converte, por sua vez, em fator 
de coesão e afirmação. Este processo de integração, tão característico desta sociedade, se desenvolve, além disso, sem um terror aberto: a democracia consolida a dominação mais firmemente do que o absolutismo. A liberdade administrada e a repressão dos instintos se transformam em instrumentos fundamentais para 0 aumento incessante da produtividade.

Mas esta produtividade econômica e tecnológica se transforma em destruição: não apenas nas guerras, mas destruição do homem em geral e da natureza; exaustão de matérias primas, de forças de trabalho, poluição do ar, da água e violência generalizada. A sociedade de consumo, como também são chamadas as sociedades industriais avançadas, se caracteriza, ao mesmo tempo, pela produção e destruição em grande escala. Graças ao progresso tecnológico e à racionalização do trabalho e das empresas, a produção não deixa de aumentar. As necessidades políticas da sociedade se transformam em interesses e necessidades dos indivíduos a tal ponto que o sistema como um todo se apresenta como a própria personificação da razão. Contrariando esta autoimagem da sociedade, Marcuse afirma:

\footnotetext{
Não obstante, essa sociedade é irracional como um todo. Sua produtividade é destruidora do livre desenvolvimento das necessidades e faculdades humanas; sua paz, mantida pela constante ameaça de guerra; seu crescimento, dependente da repressão das possibilidades reais de amenizar a luta pela existência (1982, p. 14).
}

Os recursos intelectuais e materiais necessários para essa repressão, na sociedade industrial avançada, são incomensuravelmente maiores do que nas etapas históricas anteriores; portanto, o alcance da dominação da sociedade sobre o indivíduo é extremamente mais eficiente, como também já denunciara Horkheimer em Eclipse da razão (2000, p. 131-133). Essa sociedade se distingue das anteriores pela capacidade de subjugar as forças sociais críticas ou de oposição mais pela tecnologia do que pelo terror; mais pela eficiência do sistema técnico-científico do que pela opressão explícita. Em resumo, um dos aspectos mais paradoxais dessa sociedade é "o caráter racional de sua irracionalidade" (MARCUSE, 1982, p. 29).

Segundo Marcuse, esta sociedade industrial pode ser denominada também de "sociedade sem oposição": nela tudo está padronizado, uniformizado, perfeitamente integrado segundo normas comuns. Tudo nela, homens e coisas, aparece como produto do conformismo social. Neste estágio, os direitos e as liberdades perdem sua vitalidade e se esvaziam de seu conteúdo. A independência de pensamento e o direito à oposição política perdem sua função crítica, no momento em que a organização dessa sociedade a torna cada vez mais apta a satisfazer as necessidades individuais (MARCUSE, 1982, 
p. 23). O totalitarismo e a uniformização aumentam, tanto no plano político como no técnico-econômico. As necessidades dos indivíduos estão condicionadas: criam-se falsas necessidades, impostas pelos interesses dos grupos sociais dominantes; bens de consumo de todo tipo, produzidos segundo as "leis de mercado", são eficientemente impostos à existência cotidiana dos indivíduos. O desfecho deste processo é a "euforia na infelicidade": a maioria das necessidades e atividades comuns do cotidiano, bem como as diversas opções de lazer disponíveis nesta sociedade pertence a essa categoria de falsas necessidades. De acordo com Marcuse:

Tais necessidades têm um conteúdo e uma função sociais determinados por forças externas sobre as quais o indivíduo não tem controle algum; o desenvolvimento e a satisfação dessas necessidades são heterônomos. Independentemente do quanto tais necessidades se possam ter tornado do próprio indivíduo, reproduzidas e fortalecidas pelas condições de existência; independentemente do quanto ele se identifique com elas e se encontre em sua satisfação, elas continuam a ser o que eram de início - produtos de uma sociedade cujo interesse dominante exige repressão (1982, p. 26).

O contraste entre necessidades satisfeitas e não satisfeitas, entre o dado e o possível, se atenua. Disso resulta o "nivelamento" das classes sociais, com a conseqüente homogeneização ideológica de seus interesses políticos e sociais. O conformismo se torna tão generalizado e tão profundamente arraigado nos hábitos cotidianos, que qualquer inconformismo ou insatisfação parece um sintoma de neurose. Nessa sociedade, o indivíduo acaba despojado de toda personalidade, não tem espessura nem relevo, está perfeitamente nivelado, ou seja, é "unidimensional".

Marcuse denuncia essa sociedade unidimensional como cerceadora da liberdade e da individualidade, portanto como uma sociedade com traços totalitários:

Em virtude do modo pelo qual organizou a sua base tecnológica, a sociedade industrial contemporânea tende a tornar-se totalitária. Pois totalitária não é apenas uma coordenação terrorista da sociedade, mas também uma coordenação técnico-econômica não-terrorista que opera através da manipulação das necessidades por interesses adquiridos. Impede, assim, o surgimento de uma oposição eficaz ao todo. Não apenas uma forma específica de governo ou direção partidária constitui totalitarismo, mas também uma sistema específico de produção e distribuição que bem pode ser compatível com o 'pluralismo' de partidos, jornais, 'poderes contrabalançados' etc (1982, p. 24-25). 
Podemos perceber que, para Marcuse, as sociedades industriais avançadas são "totalitárias" em virtude não do domínio explicitamente político, mas porque elas operam um aparato técnicoeconômico que impede o surgimento de alternativas ao modo de produção existente. Esta concepção pode induzir à crítica de um certo determinismo tecnológico em sua argumentação, mas acreditamos que este não é o caso de Marcuse. Para ele, as sociedades capitalistas avançadas são totalitárias porque o modo de produção capitalista e os interesses de classe utilizam a tecnologia para manipular as necessidades, "doutrinar" os indivíduos, integrar a forças potenciais de oposição e administrar o todo da sociedade de acordo com seus próprios interesses. Neste sentido, as sociedades capitalistas avançadas são totalitárias na medida em que são inteiramente controladas pela hegemonia do capital. Na concepção de Marcuse, o capital controla o Estado, os meios de comunicação, a educação e os outros aparatos ideológicos e instituições sociais, utilizando-os para seus fins de maximização do lucro e mantendo o controle social pela eliminação dos pensamentos de oposição e pela integração dos indivíduos no sistema capitalista de produção e de consumo.

Marcuse afirma que "a racionalidade tecnológica revela o seu caráter político" ao se tornar o principal instrumento de controle social, "criando um universo verdadeiramente totalitário no qual sociedade e natureza, corpo e mente são mantidos num estado de permanente mobilização para a defesa desse universo" (1982, p. 37). Isto sugere a muitos que é a racionalidade tecnológica que cria o universo totalitário. No entanto, Marcuse acrescenta também que a sociedade capitalista avançada é um universo político, que a tecnologia tal qual foi desenvolvida por essa sociedade é apenas e tão-somente um projeto histórico específico:

\begin{abstract}
Como um universo tecnológico, a sociedade industrial desenvolvida é um universo político, a fase mais atual da realização de um projeto histórico específico - a saber, a experiência, a transformação e a organização da natureza como o mero material de dominação. Ao se desdobrar, o projeto molda todo o universo da palavra e da ação, a cultura intelectual e material. No ambiente tecnológico, a cultura, a política e a economia se fundem num sistema onipresente que engolfa ou rejeita todas as alternativas. O potencial de produtividade e crescimento desse sistema estabiliza a sociedade e contém o progresso técnico dentro da estrutura de dominação. A racionalidade tecnológica terse-á tornado racionalidade política (1982, p. 19).
\end{abstract}

Assim, a tecnologia é estruturada e constituída pelos interesses políticos e econômicos que ela ajuda a promover; portanto, em uma sociedade capitalista os interesses políticos e econômicos de 
dominação determinam o projeto tecnológico dessa sociedade. Uma vez moldada por esses interesses, a tecnologia torna-se relativamente autônoma e adquire uma força e uma dinâmica próprias. Dessa forma, a sociedade contemporânea deve ser vista não como produto de um determinismo tecnológico abstrato e ahistórico que submete todas as outras esferas da vida social, mas como uma síntese de capitalismo e tecnologia que constitui uma nova e específica forma de controle social e totalitarismo.

O uso do adjetivo "totalitária" em relação à sociedade capitalista avançada é proposital em Marcuse. Durante a Guerra Fria, e até hoje, vemos tal termo ser utilizado pelos governos e pelos meios de comunicação dos países capitalistas apenas para denotar as sociedades fascistas e comunistas, ou as sociedades culturalmente diferenciadas em relação à cultura ocidental. Marcuse o utiliza em relação às sociedades liberal-democráticas do Ocidente para denunciar sua organização econômica e social como uma forma específica de totalitarismo entre outras. Embora tal extensão do termo corra o risco de esvaziá-lo de sua força crítica, acreditamos que Marcuse o utiliza como um conceito operacional que permite diversas perspectivas críticas sobre a sociedade capitalista contemporânea. Através dele, podemos perceber o caráter totalitário de sua forma de organização e mostrar que o controle pelo capital das esferas política, social e cultural e a nova síntese de capital e tecnologia são as novas formas de dominação e controle social.

\section{A atualização da crítica da cultura afirmativa}

Simultaneamente ao desenvolvimento totalitário da base tecnológica e produtiva do capitalismo industrial avançado, ocorre uma integração dos indivíduos no âmbito da cultura. Nesta também se manifesta o fenômeno de uniformização e integração, característico da sociedade unidimensional. Marcuse estuda este fenômeno de uniformização cultural sob o nome de dessublimação repressiva, que consiste no processo através do qual "o progresso da racionalidade tecnológica está liquidando os elementos de oposição e transcendentes da 'cultura superior'". O progresso da sociedade tecnológica acaba por invalidar a sua cultura superior:

A celebração da personalidade autônoma, do humanismo, do amor trágico e romântico parece ser o ideal de uma etapa superada do desenvolvimento. O que está ocorrendo agora não é a deterioração da cultura superior numa cultura de massa, mas a refutação dessa cultura pela realidade. A realidade ultrapassa sua cultura (1982, p. 69).

A realidade atual absorve a cultura liberal clássica, uma vez que o homem moderno pode, graças à racionalidade tecnológica, superar os heróis e semi-deuses de então. A realidade de hoje supera a ficção de 
antes. Mas, ao mesmo tempo, todo o potencial de esperança e de verdade profunda que continham as sublimações da cultura superior se encontra destruído. O antagonismo entre a realidade social e o mundo da cultura desaparece com a subordinação deste à realidade existente. A esfera desta "outra dimensão" da realidade que era a cultura superior diminui constantemente (MARCUSE, 1982, p. 70). Seus elementos de oposição, de alteridade, de transcendência com relação à realidade social vivida, não são rechaçados ou mesmo negados, mas sim assimilados, incorporados à ordem estabelecida. 0 cultural deixa de ser valor para se tornar realidade, e perde com isso toda sua força de questionamento. O âmbito cultural já não garante a bidimensionalidade do homem porque está integrado, dirigido e fragmentado pela sociedade de consumo. A grandeza da arte e literatura livres, os ideais do humanismo, a realização da personalidade; todos esses valores culturais, que deveriam estar a serviço do homem, são utilizados pela sociedade para assegurar sua coesão e a manutenção do status quo, reprimindo qualquer transformação social mais radical. Os meios de comunicação de massa, que só conhecem como denominador comum a forma mercantil, reduzem todas essas criações culturais ao valor de troca.

Dessa maneira, se reduz de forma gradual o domínio do sublimado, que constituía, em nome do ideal, uma denúncia da condição humana. A cultura superior (idealista) se degrada em cultura material, convertendo-se a partir daí em integrante dessa matéria mental que os meios de comunicação difundem para alcançar seus objetivos econômicos de lucratividade. Para Marcuse, a cultura superior do Ocidente foi uma cultura pré-tecnológica tanto em seu sentido funcional quanto no sentido cronológico: "sua validez resultou da experiência de um mundo que não mais existe e que não pode ser reconquistado por estar, num sentido estrito, invalidado pela sociedade tecnológica" (1982, p. 71).

Tal como se apresenta na cultura superior da época burguesa, a consciência artística é, em certo sentido, uma consciência alienada, já que rejeita o mundo do progresso e dos negócios, que é o mundo burguês por excelência. No entanto, esta forma cultural burguesa não pode mais ser recuperada a não ser como lembrança fantasmagórica de possibilidades perdidas:

É uma cultura antiquada e ultrapassada, e somente sonhos e regressões infantis podem recuperá-la. Mas essa cultura é também, em alguns de seus pontos decisivos, póstecnológica. Suas imagens e posições mais avançadas parece sobreviverem à sua absorção em comodidades e estímulos administrados; continuam assombrando a consciência com a possibilidade de seu renascimento na consumação do progresso técnico. São a expressão da alienação livre e consciente das formas estabelecidas de vida com a qual a 
literatura e as artes se opuseram a essas formas até mesmo onde as adornaram (MARCUSE, 1982, p. 72).

Na sociedade capitalista avançada, ao contrário de seu conceito na teoria marxista, esta alienação artística "é a transcendência consciente da existência alienada - uma alienação distanciada e mediatizada", não um romantismo nostálgico, mas a expressão de uma dimensão distinta, para além do cotidiano pragmático da sociedade vigente. A arte, porém, assim como a cultura como um todo, está hoje em vias de perder este valor de transcendência com relação à realidade estabelecida. A capacidade de assimilação da sociedade industrial avançada é tão ilimitada que chegou a fazer do liberalismo a nova forma do totalitarismo cultural: no domínio da cultura, o novo totalitarismo se manifesta precisamente num pluralismo harmonizador, no qual as obras e as verdades mais contraditórias coexistem pacificamente com indiferença" (MARCUSE, 1982 , p. 73). Essa indiferença resultante é, no entanto, a proteção mais eficiente para os valores estabelecidos. Segundo Zizek (2006, p. 71-79), em nossa sociedade pós-política, o "multiculturalismo", que parece hegemônico nos trabalhos acadêmicos e nos meios de comunicação de massa, atualiza e legitima aquela tendência ao "pluralismo harmonizador" que Marcuse já denunciara em seu artigo sobre a tolerância repressiva (apud WOLFF; MOORE; MARCUSE, 1970, p. 87-126).

Talvez se possa argumentar que, apesar de tudo, é positivo que a cultura na atualidade possa ser acessível ao grande público; que as grandes obras da literatura e da arte possam, graças aos modernos meios de comunicação de massa, sair dos museus e reencontrar-se com a vida cotidiana. Marcuse responde a esse argumento dos "neoconservadores", assinalando que estes clássicos assim popularizados, apesar de voltarem à vida da qual se alienavam, ao mesmo tempo mudam de índole, perdendo o poder antagônico e negativo que constituía sua verdade:

\footnotetext{
É verdade, mas voltando à vida como clássicos, eles voltam à vida diferentes de si mesmos; são privados de sua força antagônica, do alheamento que foi a própria dimensão de sua verdade. O intento e a função dessas obras foram, assim, fundamentalmente modificados. Se antes estavam em contradição com o status quo, essa contradição se mostra hoje aplanada (1982, p. 76).
}

Essa "reconciliação cultural" estabelece uma igualdade de acesso, no entanto, na mesma medida, sustenta a dominação. Os autores e as obras clássicas, uma vez comercializadas, se transformam em elementos da sociedade de consumo. A distância entre objeto de arte e produto de consumo deixa de existir e tudo se nivela no mercado. É 
no exato momento em que a sociedade de consumo parece prestar um serviço à arte e à cultura, ao colocar suas criações ao alcance do grande público, que retira o seu potencial de negação. A arte e a cultura se convertem, através desse processo, em simples peças da "engrenagem de uma máquina cultural que remodela seu conteúdo" (MARCUSE, 1982, p. 77). A sociedade industrial, regida pelo progresso técnico, diminui progressivamente a miséria material, mas, igualmente nela, a negação é negada e a cultura superior acaba despojada de sua transcendência. Os valores culturais, segundo Marcuse, são retirados do campo da metafísica e assimilados ao nível do cotidiano, fechando a possibilidade da "Grande Recusa" (1982, p. 75). No universo tecnológico, os problemas metafísicos se reduzem à análise do sentido das palavras:

\begin{abstract}
A análise lógica e lingüística demonstra que os velhos problemas metafísicos são ilusórios; a busca do 'significado' das coisas pode ser reformulado como a busca do significado das palavras, e o universo estabelecido da palavra e do comportamento pode fornecer critérios perfeitamente adequados para a resposta (MARCUSE, 1982, p. 81).
\end{abstract}

O sistema bloqueia toda escapatória a este mundo da racionalidade instrumental e o aumento progressivo da satisfação material adormece todo desejo de liberdade. A cultura superior se transforma em cultura de massa, sofre uma "dessublimação" crescente, o transcendente se integra aos afazeres do cotidiano para perder-se no anonimato e no comercializável. A sociedade industrial avançada, no entanto, não teme esta invasão do transcendente, pois está segura de poder digeri-lo e assimilá-lo; ela opera a partir de uma posição de força: a sociedade tecnológica concede "mais do que antes pelo fato de os seus interesses se terem tornado os impulsos mais íntimos de seus cidadãos e porque os prazeres que ela concede promovem a coesão e o contentamento sociais" (MARCUSE, 1982, p. 82).

É importante notar a mudança de postura de Marcuse frente a este processo de integração cultural. Em seu artigo da década de 30, "Sobre o caráter afirmativo da cultura", Marcuse utilizou a dicotomia entre "cultura", entendida como a esfera dos valores espirituais, e "civilização", entendida como a esfera do mundo do trabalho e da necessidade, para criticar a filosofia idealista da cultura, que concebia a primeira esfera como radicalmente distinta da segunda. A cultura idealista burguesa se equivocava por ignorar completamente 0 condicionamento social de toda produção intelectual e artística. Essa cultura idealista é denominada por Marcuse de cultura afirmativa:

Cultura afirmativa é aquela cultura pertencente à época burguesa que no curso de seu desenvolvimento levaria a distinguir e elevar o mundo espiritual-anímico, nos termos de 
uma esfera de valores autônoma, em relação à civilização. Seu traço decisivo é a afirmação de um mundo mais valioso, universalmente obrigatório, incondicionalmente confirmado, eternamente melhor, que é essencialmente diferente do mundo de fato da luta diária pela existência, mas que qualquer indivíduo pode realizar para si "a partir do interior", sem transformar aquela realidade de fato. Somente nessa cultura as atividades e os objetos culturais adquirem sua solenidade elevada tanto acima do cotidiano: sua recepção se converte em ato de celebração e exaltação (1997, v. 1, p. 95-96).

A cultura afirmativa burguesa prometia a felicidade e a harmonia, mas apenas no plano do imaginário, da ilusão: era preciso, portanto, defendia Marcuse, superar (aufheben) essa cultura, realizando na prática as promessas nela incorporadas, e transformando, num certo sentido, a arte em vida. Ao final da década de 60, porém, Marcuse (1981, p. 109) se assusta com as conseqüências dessa dessublimação no capitalismo industrial avançado e recomenda aos combatentes de sua época que renunciem a qualquer projeto de dissolução da cultura: a revolução cultural, "para manter e intensificar o 'poder da negação', o poder subversivo da arte, deve manter e intensificar o poder alienante da arte", pois só dessa forma pode testemunhar contra a alienação objetiva do real. Nessa fase, então, Marcuse retoma a distinção entre cultura e civilização, agora não mais para denunciar a autonomia idealista da cultura afirmativa burguesa, mas para denunciar a perda dessa autonomia: a sociedade unidimensional cumprira bem demais o programa revolucionário do jovem Marcuse dos anos 30, realizando de maneira totalitária aquela superação que ele defendera (ROUANET, 1989, p. 203).

A cultura idealista burguesa, evidentemente era ideológica, no sentido clássico marxista de "falsa consciência", pois ao transferir para o plano espiritual um conceito de liberdade irrealizável nas condições sociais existentes, inibia a compreensão totalizante dessas condições e contribuía para perpetuá-las. A satisfação estética e intelectual da classe dominante era assegurada através das privações impostas à maioria, isto é, à classe trabalhadora, cujo trabalho gerava o excedente sem o qual a esfera da cultura careceria de base material. Sendo fruto da divisão repressiva entre trabalho físico e trabalho intelectual, a cultura afirmativa contribuía para dissimular a realidade dessa divisão, apontando para uma harmonia ideal além das realidades de um mundo dicotômico:

Mas essa cultura alienada continha, em sua alienação mesma, um momento de verdade e a promessa de uma ordem não-alienada. Exatamente por funcionar como uma esfera relativamente autônoma acima e além da civilização, representava uma perspectiva de transcendência, uma 
normatividade, uma paidea, uma reserva de valores espirituais que apropriados historicamente poderiam conduzir a civilização a autotranscender-se em direção à realização concreta dos ideais culturais (ROUANET, 1989, p. 203-204).

A dimensão crítica da cultura residia precisamente nessa tensão entre as duas esferas da transcendência e da imanência; tensão irredutível porque a cultura sempre continha um excedente de significação que ultrapassava todas as suas realizações históricas. A cultura idealista, ao mesmo tempo transfigurando espiritualmente a liberdade $e$ ocultando a heteronomia efetiva da esfera da civilização, propunha um ideal de autonomia que funcionava como um fermento subversivo capaz de contestar a realidade estabelecida. Nas condições atuais do capitalismo avançado, desaparece o antagonismo entre a esfera da cultura e da civilização. A cultura foi incorporada integralmente à esfera da civilização; suas manifestações mais críticas foram absorvidas pelo universo instrumental. Seus valores, antes subversivos, constituem hoje elementos de coesão e controle social. Cessou o distanciamento que assegurava a verdade da cultura. A dessublimação repressiva produziu finalmente uma "consciência feliz" e satisfeita: "a 'consciência infeliz' da humanidade, que latejava na cultura como a memória da injustiça e como a antevisão de uma justiça futura, foi extirpada, integrando-se de forma não problemática na 'consciência feliz' da ordem unidimensional" (ROUANET, 1989, p. 204). Como bem observa Zizek (2006, p. 111), na era da "dessublimação pós-moderna" os indivíduos são controlados não por um superego repressivo quanto à realização de seus desejos mais profundos, mas ao contrário, são regidos pelo "imperativo de gozar" a todo custo: a nova subjetividade pós-moderna comporta como seu elemento mais característico um superego que nos ordena "que adoremos fazer o que temos de fazer" (ZIZEK, 2006, p. 113). O fetichismo da mercadoria se estende, no capitalismo tardio, à esfera da cultura e da subjetividade; e a forma mercantil invade a derradeira reserva de autonomia, regida (mesmo no plano do imaginário) por leis que excluíam o valor de troca.

\section{A crítica da ideologia no capitalismo tardio}

$\mathrm{Na}$ esfera ideológica e política, o processo de unidimensionalização apontado por Marcuse se manifesta de forma mais clara na integração da classe operária. Essa integração se dá ao nível da consciência, na medida em que o proletariado do capitalismo avançado introjetou os valores do sistema econômico e político, mas sobretudo integração objetiva, na medida em que a classe 
trabalhadora se beneficia crescentemente, de fato e não apenas ideologicamente, da prosperidade geral, como observa Rouanet:

\footnotetext{
Por sua posição central no processo produtivo, a classe operária não perdeu sua significação objetiva como agente histórico da transformação. Mas se continua sendo uma classe revolucionária "em si", não o é mais "para si", isto é, subjetivamente. Deixou de ser a negação viva do sistema. Com a assimilação do proletariado, fecha-se o espaço da contestação radical. Esse fechamento constitui o paradigma e a precondição de todas as outras formas de integração que caracterizam, em diferentes níveis, a sociedade unidimensional (1989, p. 202).
}

Marx sempre considerou o proletariado como a classe revolucionária por excelência. Sendo a principal vítima da exploração capitalista, e sem perspectivas de emancipação no quadro do mundo burguês, ela seria o sujeito da transformação social. Marcuse nota, porém, que nas sociedades industriais avançadas já não ocorre o mesmo: na "sociedade afluente" a classe operária está ligada ao sistema das necessidades, mas não a sua negação. Essa classe já não experimenta a necessidade de transformar a sociedade capitalista, uma vez que está integrada ao sistema. O desenvolvimento do mundo capitalista alterou a estrutura e a função das classes sociais, burguesia e proletariado, até o ponto de despojá-las de seu papel histórico de agentes da transformação social. Cada vez mais, "um interesse predominante na preservação e no melhoramento do status quo institucional une os antigos antagonistas nos setores mais avançados da sociedade contemporânea" (MARCUSE, 1982, p. 16). A idéia de uma evolução quantitativa, lenta e gradual do capitalismo substitui progressivamente a idéia de uma mudança qualitativa, revolucionária. A sociedade capitalista desenvolvida teria tido êxito em integrar a classe operária a seu sistema, principalmente no que se refere a suas organizações sindicais. Assim, conseguiu eliminar a distinção entre interesse real e interesse imediato dos explorados e, junto com esta distinção, a necessidade de transcender as reivindicações salariais ou de condições de trabalho para fazê-las passar do plano econômico ao político.

No capitalismo avançado, os controles sociais foram introjetados a tal ponto que até o protesto individual foi afetado em suas raízes: a negativa intelectual ou emocional de compactuar com os valores socialmente aceitos parece impotente, ou então um sintoma neurótico. Essa é a dimensão sócio-psicológica do "fechamento do universo político": "o desaparecimento das forças históricas que, na fase anterior da sociedade industrial, pareceu representarem a possibilidade de novas formas de existência" (MARCUSE, 1982, p. 30). Mas, segundo Marcuse, até mesmo o termo "introjeção" talvez 
seja inadequado para expressar esse fenômeno de integração das classes e dos indivíduos ao sistema: ele ainda pressupõe algo "exterior" que é transferido ao "interior"; indica ainda a existência de algo como uma "liberdade interior" que se oporia às idéias e valores impostos pela sociedade aos indivíduos. Na sociedade industrial avançada, no entanto, esse espaço "privado" se apresenta invadido pela realidade tecnológica que torna mecânicos os comportamentos dos indivíduos. Ao fim desse processo, temos não o ajustamento do indivíduo, mas sua identificação com a sociedade como um todo; a "dimensão interior" da mente, na qual a oposição ao universo estabelecido poderia se enraizar, é totalmente esvaziada e conquistada.

É fundamental ressaltar que, para Marcuse, a perda dessa dimensão de negatividade e de oposição é a contrapartida ideológica do próprio desenvolvimento material da sociedade industrial avançada: "o impacto do progresso transforma a Razão em submissão aos fatos da vida e à capacidade dinâmica de produzir mais e maiores fatos do mesmo tipo de vida" (1982, p. 31). A conseqüência disso é que o próprio conceito de alienação é colocado em xeque: no capitalismo avançado os indivíduos se identificam com o tipo de existência que lhes é imposto e têm satisfação com a sua manutenção e aprimoramento. Essa identificação não é uma "ilusão"; longe de ser apenas subjetiva, ela se dá no nível objetivo, é uma realidade. 0 fenômeno da absorção da ideologia pela realidade não significa, porém, o "fim da ideologia". Em sentido específico, a cultura industrial avançada é mais ideológica do que sua predecessora - a sociedade liberal clássica -, uma vez que, atualmente, a "ideologia está no próprio processo de produção (...) O aparato produtivo e as mercadorias e serviços que ele produz 'vendem' ou impõem o sistema social como um todo" (MARCUSE, 1982, p. 31-32).

A unidimensionalização da realidade é, portanto, um processo objetivo e deriva do aparato tecnológico e econômico capitalista: ele dá origem a "um padrão de pensamento e comportamento unidimensionais no qual as idéias, as aspirações e os objetivos que por seu conteúdo transcendem o universo estabelecido da palavra e da ação são repelidos ou reduzidos a termos desse universo" (MARCUSE, 1982, p. 32). As idéias e valores que não se encaixam nessa sociedade estabelecida são redefinidos pela racionalidade do sistema dado e de sua extensão quantitativa.

\section{As possibilidades da emancipação social}

A principal conseqüência das integrações cultural e ideológica, características da sociedade unidimensional, é a dificuldade de pensar a prática emancipatória. Nesta sociedade, a teoria e a prática revolucionária se encontram divorciadas; as condições da dominação tornam quase inviável pensar a transformação social, uma vez que 
elas dificultam a identificação do sujeito histórico ao qual caberia a tarefa prática da mudança histórica. Marcuse caracteriza a "nova sociedade" do capitalismo avançado como uma combinação do Estado beligerante com o Estado do bem-estar social, uma sociedade da administração total na qual os problemas tradicionais da sociedade liberal clássica "estão sendo dissipados ou isolados, sendo controlados os elementos dissociativos" (1982, p. 38).

Nessa sociedade, os opostos convergem para as mesmas posições políticas e ideológicas. Ocorre o fenômeno, cada vez mais atual, da homogeneização da política: tanto os partidos de direita quanto os de esquerda defendem, na prática, isto é, uma vez no poder, a continuidade da mesma política econômica e da mesma noção de progresso entendido como produtividade econômica. Marcuse já denunciava que nos países do "socialismo real" a situação não era diferente, pois "a redução gradativa dos controles políticos diretos testemunha a crescente confiança na eficácia dos controles tecnológicos como instrumentos de dominação" (1982, p. 39). Os partidos de esquerda ocidentais se rendem prontamente ao sistema econômico e tecnológico e arquivam o projeto da tomada revolucionária do poder. A luta de classes é atenuada e toda mobilização se dá em torno das "ameaças externas": a sociedade capitalista avançada ostenta uma coesão e união internas desconhecidas em outras fases anteriores da sociedade industrial.

No capitalismo organizado, a racionalidade técnica está personificada, a despeito de sua irracionalidade, no aparato produtivo. Não são apenas os meios de produção e os instrumentos de trabalho que se adaptam à racionalidade técnica, mas é a própria forma do trabalho que se conforma aos procedimentos da "gerência científica". Marcuse sustenta que "nem a nacionalização nem a socialização alteram por si essa personificação física da racionalidade tecnológica; pelo contrário, esta permanece uma condição prévia para o desenvolvimento socialista de todas as forças produtivas" (1982, p. 41). Assim, fica evidente que, para Marcuse, os países ditos socialistas mantiveram a mesma forma de produção e de produtividade que prevalecia nos países capitalistas avançados ${ }^{1}$. Isto significa que, para ele, houve uma "assimilação dos dois sistemas", uma vez que se constituíram a partir da mesma base tecnológica (LOUREIRO, 1999, p. 54). O problema da teoria crítica da sociedade, nesse contexto, é saber se e como os indivíduos administrados podem se libertar do aparato técnico-econômico dominante:

Assim, deve ser novamente enfrentada a pergunta: como podem os indivíduos administrados - que levaram a sua mutilação às suas próprias liberdades e satisfações e, assim, reproduzem-na em escala ampliada - libertar-se tanto de si mesmos como de seus senhores? Como se poderá sequer 
pensar que o círculo vicioso possa ser rompido? (MARCUSE, 1982, p. 230).

A situação histórica da integração, objetiva e subjetiva, da classe trabalhadora ao sistema técnico-econômico vigente indica a dificuldade de se pensar alternativas factíveis de transformação social. Nos países em que a classe trabalhadora se encontra mais integrada ou assimilada, isto é, nos países capitalistas mais desenvolvidos, ela não representa mais a negação desse sistema. Ela é antes uma força de coesão do que de negação dessa sociedade (MARCUSE, 1982, p. 234). Em sua fase mais avançada, a dominação funciona como administração total: a vida administrada se torna "agradável" e "satisfatória" para a maioria da população, unindo, assim, as classes antes antagônicas. As metas da autodeterminação autêntica dos indivíduos e do controle social da produção e da distribuição eficaz e igualitária das necessidades acaba obscurecida pela eficiência do sistema em fornecer as mercadorias. Por outro lado, as tendências totalitárias da sociedade unidimensional tornam ineficazes as formas clássicas, modernas, de protesto, o que enfraquece cada vez mais as organizações de trabalhadores. Nessas condições, colocam-se as questões: "o que aconteceu com o sujeito da revolução? Se, de fato, a integração do trabalhador progride nos países industriais altamente desenvolvidos, teremos ainda o direito de considerar a classe trabalhadora como o sujeito histórico da revolução?" (LOUREIRO, 1999, p. 54-55).

A resposta de Marcuse a essa questão tem sido objeto de controvérsias. A análise da integração política e cultural da classe trabalhadora no capitalismo avançado e seu apoio - aliás, de forma alguma acrítico - ao movimento estudantil do final da década de 60, poderiam nos fazer acreditar que Marcuse já não tomava aquela classe como classe revolucionária ${ }^{2}$. No entanto, acreditamos que, dentro da lógica do pensamento marcuseano, a classe trabalhadora continuava sendo a principal interessada numa mudança revolucionária, embora sua consciência estivesse contaminada pela ideologia do sistema técnico, econômico e social estabelecido. Embora esta classe não estivesse propensa à "grande recusa" das idéias e valores vigentes na sociedade industrial avançada, Marcuse também não imaginou ingenuamente, como muitos acreditam, que o movimento estudantil e os "novos movimentos sociais" seriam os sujeitos de qualquer transformação histórica radical. Marcuse via esses grupos apenas como catalisadores da insatisfação geral, por estarem, de certa forma, excluídos das principais benesses oferecidas pelo sistema à classe trabalhadora assimilada e tornada conservadora. Mas, apesar de seu regular "pessimismo", Marcuse continuava tentando detectar, no próprio processo histórico concreto, as forças que poderiam contestar o sistema como um todo: 
Contudo, por baixo da base conservadora popular está o substrato dos párias e estrangeiros, dos explorados e perseguidos de outras raças e de outras cores, os desempregados e os não-empregáveis. Eles existem fora do processo democrático; sua existência é a mais imediata e a mais real necessidade de pôr fim às condições e instituições intoleráveis. Assim, sua oposição é revolucionária ainda que sua consciência não o seja. Sua oposição atinge o sistema de fora para dentro, não sendo, portanto, desviada pelo sistema, é uma força elementar que viola as regras do jogo e, ao fazê-lo, revela-o como um jogo trapaceado (1982, p. 235).

Muito dessa análise poderia ser transportada para a atualidade, quando o número dos "excluídos" do sistema aumenta na mesma medida em que o capitalismo avança globalmente. Podemos, também, repetir hoje a afirmação de Marcuse, se referindo à possibilidade de o sistema entrar em seu estágio terminal, de que "nada indica que será um bom fim". Continuamos sem parâmetros para visualizar o curso futuro do capitalismo em sua aventura de hegemonia mundial. Contudo, devemos nos lembrar de que, segundo Marcuse, a teoria crítica da sociedade não pode ser "positiva", sob pena de sucumbir aos fatos dados: ela pode definir "as possibilidades históricas; até mesmo as necessidades históricas; mas a realização destas só pode estar na prática que responde à teoria, e, na atualidade, a prática não dá tal resposta" (1982, p. 232). Enquanto a unidade entre teoria e prática não se torna realizável no mundo histórico concreto, temos que manter a teoria sintonizada com os movimentos que representam, ou podem vir a representar, a sobrevivência da razão crítica no mundo social.

\section{Eros como princípio de emancipação}

Em Eros e civilização, obra publicada originalmente em 1955, Marcuse parte do pressuposto de que a sociedade industrial avançada já detém todas as possibilidades técnicas para transformar a vida humana de simples luta pela existência, isto é, pela satisfação de suas necessidades e carências básicas (Ananké ou Lebensnot), em uma vida de liberdade, gratificação e prazer (1999a, p. 37). As restrições e repressões impostas aos indivíduos pela necessidade de garantir a sobrevivência já não fazem sentido no estágio de progresso econômico e social do capitalismo tardio. No entanto, seria ingênuo acreditar que essas possibilidades técnicas sejam suficientes para fazer desaparecer a pobreza e para operar a passagem histórica para uma nova civilização, uma civilização não-repressiva. Reinterpretando a teoria de Freud acerca do processo civilizatório humano, Marcuse tenta explicitar os mecanismos de defesa utilizados pela sociedade repressiva contra o advento dessa nova sociedade e 
investigar as possibilidades de emancipação da sensibilidade rumo a uma sociedade não-repressiva. Segundo ele, quanto mais se aproxima a possibilidade concreta de libertar os homens das coações justificadas antes pela escassez, maior é a necessidade da sociedade repressiva de reforçar as coações historicamente impostas, modernizando-as e introjetando-as de maneira mais eficaz na consciência dos indivíduos:

\begin{abstract}
Mas quanto mais perto se encontra a possibilidade real de emancipar o indivíduo das restrições outrora justificadas pela escassez e imaturidade, tanto maior é a necessidade de manutenção e dinamização dessas restrições, para que a ordem estabelecida de dominação não se dissolva. A civilização tem de se defender contra o espectro de um mundo que possa ser livre (...) A defesa consiste, principalmente, num fortalecimento dos controles não tanto sobre os instintos, mas sobre a consciência, a qual, se se permitir que fique livre, poderá reconhecer o trabalho de repressão mesmo nas maiores e melhores satisfações de necessidades (MARCUSE, 1999a, p. 94-95).
\end{abstract}

Assim, à coação sobre os instintos, imposta pela escassez, se juntaram as coações impostas pela civilização por meio da divisão do trabalho. A repressão imposta pelo princípio de realidade e a repressão devida à dominação, isto é, o interesse de proteger os interesses particulares de grupos específicos, se conjugaram para perpetuar a repressão. Como resultado, a sociedade continua a reprimir crescentemente os instintos, uma vez que a noção de progresso que sustenta a existência dessa civilização assegura a sobrevivência e o reforço da dominação e do trabalho alienado. Para esse fim, "as instituições históricas específicas do princípio de realidade e os interesses específicos de dominação introduzem controles adicionais acima e além dos indispensáveis à associação civilizada humana". A esses controles adicionais, impostos pelas instituições específicas de dominação, Marcuse deu o nome de maisrepressão (1999a, p. 52-53).

Segundo Marcuse, a mais-repressão assumiu diferentes formas em diferentes fases históricas. Sua manifestação contemporânea é o que ele denominou de princípio de desempenho. Esta designação foi escolhida por Marcuse para acentuar que, "sob o seu domínio, a sociedade é estratificada de acordo com os desempenhos econômicos concorrentes dos seus membros" (1999a, p. 58). A repressão oriunda do interesse de dominação foi tornada invisível pela extensão ideológica do conceito de necessidade ou escassez, que passou a incluir não somente as necessidades advindas do controle da natureza como também as resultantes do controle sobre os homens, ambas assimiladas a necessidades naturais, e como tal, não suscetíveis de modificação histórica. A sociedade unidimensional, 
portanto, garante a manutenção da dominação naturalizando um princípio de realidade específico, a saber, o princípio de desempenho típico do capitalismo industrial avançado e obtendo a adesão subjetiva dos indivíduos a esse princípio. Até a fase do capitalismo liberal, a forma subjetiva de integração dos indivíduos aos interesses do poder, ou seja, a adequação do pólo subjetivo ao pólo objetivo, era mediatizada pela família, que funcionava como agência psíquica da sociedade. Esta forma mediatizada de integração do indivíduo à sociedade ainda permitia uma última reserva de vida privada e podia ainda assegurar a formação de personalidades relativamente autônomas e auto-determinadas. Na fase do capitalismo tardio ou organizado, porém, a unidimensionalização leva à expulsão desses últimos redutos de transcendência e auto-determinação. É a própria sociedade que, através de suas agências, socializa os indivíduos para se adequarem ao princípio de realidade imposto. Esta explicação nos ajuda a compreender a impotência atual das famílias - e das instituições educacionais, às quais as famílias delegavam esta tarefa - para influir na formação da consciência e da visão de mundo de seus filhos: a família e a escola não têm mais condições de competir com o poder de formação das consciências que está concentrado nos meios de comunicação de massa (MARCUSE, 1999a, p. 96-97). As possíveis bases para o antagonismo entre o indivíduo e a sociedade são eliminadas pela modificação do aparelho pulsional. Através dessa modificação, o ciclo filogenético da dominação-rebelião-dominação não é mais apenas um movimento cíclico, mas um "progresso em dominação". O indivíduo, na sociedade regida pelo princípio de desempenho, introjeta o "logos da dominação" como um princípio impessoal, objetivo, universal e racional:

\begin{abstract}
Por fim, sob o domínio do princípio de desempenho plenamente desenvolvido, a subordinação apresenta-se como que efetivada através da divisão social do trabalho (...) A sociedade emerge como um sistema duradouro e em expansão de desempenhos úteis; a hierarquia de funções e relações adquire a forma de razão objetiva: a lei e a ordem com a própria vida da sociedade. No mesmo processo, também a repressão é despersonalizada: a restrição e arregimentação do prazer passam agora a ser uma função (e resultado "natural") da divisão social do trabalho (MARCUSE, 1999a, p. 91).
\end{abstract}

A sociedade unidimensional representa, para Marcuse, a última etapa do logos da dominação e, ao mesmo tempo, uma realidade qualitativamente nova no ciclo filogenético. Até então, a repressão era legitimada por uma ideologia que justificava o poder em virtude das imensas exigências da luta pela existência. No capitalismo avançado, a legitimação se fundamenta na abundância, na eficácia 
com a qual satisfaz as "necessidades" humanas. O sistema interioriza nas consciências, não mais os valores ascéticos que levavam os indivíduos a aceitar a frustração de suas necessidades, mas as próprias necessidades apresentadas como valores em si mesmos. Como o aparato técnico-econômico é suficientemente eficiente para gratificar essas necessidades (verdadeiras ou falsas - aqui já pouco importa) com um mínimo de esforço, o sistema é visto como a própria objetivação da razão. Parece não haver mais nenhuma tensão entre desejo e realização: na medida em que o indivíduo é socializado para desejar certos bens materiais e o sistema produtivo lhe fornece estes bens na medida de seu desejo, o antigo antagonismo entre sujeito e objeto, entre aspiração e realidade desaparece. Diferentemente do capitalismo liberal, quando a opressão assumia a forma de privação, no capitalismo tardio a opressão assume a forma de abundância. Dessa maneira, a repressão característica da sociedade unidimensional não pode ser facilmente percebida, pois sua confirmação é a própria realidade material e econômica promovida por esta sociedade. Há uma identificação dos indivíduos justamente com o poder do aparato produtivo que os oprime: "a incorporação econômica e política dos indivíduos no sistema hierárquico do trabalho é acompanhada de um processo instintivo em que os objetos humanos de dominação reproduzem sua própria opressão" (MARCUSE, 1999a, p. 93).

$\mathrm{Na}$ sociedade da abundância, não se trata mais de legitimar a impossibilidade da gratificação, mas de utilizar a própria gratificação como forma de legitimação. Para Marcuse, esta acaba por assumir o caráter de dessublimação, uma vez que substitui a satisfação mediata pela satisfação imediata (1982, p. 82). Sua finalidade, no entanto, não é promover uma libertação real dos indivíduos, mas controlá-los e aprisioná-los de maneira mais eficaz dentro da ordem estabelecida, o que permite que falemos de uma dessublimação repressiva. Esta aparece sob diversas formas; uma delas é a absorção da cultura pela civilização, ou seja, o fenômeno que chamamos de unidimensionalização da cultura: na esfera da cultura idealista, o princípio de prazer, violentado pelo princípio de realidade, continuava, não obstante, presente como nostalgia da felicidade e recordação da possibilidade de um futuro melhor. Possuía, assim, uma "força subversiva" que se manifestava em sua incompatibilidade com a sociedade existente. Na sociedade unidimensional, entretanto, ocorre uma redução progressiva do reino do sublimado no qual a condição humana era representada, idealizada e denunciada (MARCUSE, 1982, p. 70). Dessa forma, a incorporação da cultura idealizada na civilização significa uma dessublimação a serviço da repressão. Nesta nova fase histórica, o princípio de prazer não é simplesmente negado, mas sim mobilizado pelo princípio de realidade 
estabelecido. Como conseqüência, o conteúdo subversivo e negador da cultura é silenciado, dando lugar a uma cultura afirmativa.

Além da dessublimação cultural, temos também uma dessublimação repressiva no campo da sexualidade: a extensão, por parte da civilização industrial, de seu controle a regiões da consciência anteriormente livres e ao tempo de lazer permite o relaxamento dos tabus sexuais, ou seja, uma liberalização sexual. Entretanto, segundo Marcuse, esse processo é ainda repressivo, pois o corpo não deixa de ser um instrumento de trabalho, mas passa a ser também valorizado como objeto libidinal:

\begin{abstract}
Hoje, comparada com a dos períodos puritano e vitoriano, a liberdade sexual aumentou indiscutivelmente (...). Ao mesmo tempo, porém, as relações sexuais passaram a estar muito mais assimiladas com as relações sociais; a liberdade sexual harmoniza-se com o conformismo lucrativo. O antagonismo fundamental entre sexo e utilidade sexual - em si mesmo um reflexo do conflito entre o princípio de prazer e o princípio de realidade - é obnubilado pela progressiva incrustração do princípio de realidade no princípio de prazer. Num mundo de alienação, a libertação de Eros atuaria, necessariamente, como uma força destruidora e fatal - como a total negação do princípio que governa a realidade repressiva. (...) Em contraste com a destrutividade do Eros libertado, o relaxamento da moralidade sexual, dentro do sistema firmemente consolidado e controles monopolísticos, serve ao sistema (1999a, p. 95).
\end{abstract}

A partir da dessublimação repressiva da sexualidade, promovida pela sociedade unidimensional, o sexo se transforma em mercadoria e a mercadoria adquire atributos sexuais, sofre um processo de libidinização: a sexualidade invade a propaganda e envolve os objetos do cotidiano, seja nos ambientes residenciais, nas ruas ou nas empresas. Esta ressexualização da vida, no entanto, funciona num sentido favorável ao princípio de realidade, pois é acompanhada de uma contração de Eros. Este - que para Freud é uma força geral que transcende a mera função sexual - é reduzido à sexualidade, permitindo, ao mesmo tempo, uma "deserotização" geral da vida e uma liberalização do sexo. A manipulação repressiva dos instintos levada a cabo pela sociedade industrial avançada significa, portanto, dessublimar sem eliminar, de fato, a repressão (ROUANET, 1989, p. 234). O que ocorre, na prática, é a adequação do aparelho pulsional dos indivíduos aos imperativos econômicos e políticos do princípio de desempenho, isto é, do princípio de realidade específico que governa o progresso da civilização ocidental.

$\mathrm{Na}$ medida em que a sociedade unidimensional promove a manipulação repressiva dos instintos, com a finalidade de produzir consciências totalmente submissas ao princípio de desempenho, a 
possibilidade de se construir uma sociedade não-repressiva, segundo Marcuse, está na libertação pulsional, ou seja, na formação de consciências hostis a qualquer manipulação e capazes de estabelecer novas relações perceptivas com a realidade. Levando em conta que no capitalismo industrial avançado o pressuposto da escassez já não justifica a necessidade da repressão e que esta só se mantém (enquanto mais-repressão) graças ao interesse de dominação que continua presente no princípio de desempenho de nossa civilização, Marcuse reafirma a possibilidade histórica de uma nova sociedade na qual a falsa consciência unidimensional seria sucedida por uma consciência emancipada, e o poder interiorizado seria expulso do aparelho pulsional, dando lugar ao reino da liberdade:

\begin{abstract}
À luz da tendência da civilização, vista numa longa perspectiva, e à luz da própria interpretação freudiana do desenvolvimento dos instintos, esse pressuposto deve ser discutível. A possibilidade histórica de um descontrole gradual do desenvolvimento instintivo deve ser tomada seriamente em consideração, talvez mesmo a sua necessidade histórica - se acaso a civilização tem de progredir para um estágio superior de liberdade (1999a, p. 127).
\end{abstract}

O maior obstáculo à hipótese de uma civilização não-repressiva é a concepção de que a diminuição ou eliminação da repressão social privaria os indivíduos das energias necessárias ao trabalho, sem o qual a sociedade não pode sobreviver em sua luta pela sobrevivência diante da escassez. Mas com o nível de desenvolvimento das forças produtivas alcançado pela sociedade industrial avançada, o tempo de trabalho poderia ser reduzido ao mínimo. Em uma organização social não-repressiva, em que o tempo livre não seja manipulado e apropriado pela indústria cultural, poderia ocorrer uma reerotização do organismo por inteiro, para além das necessidades da sexualidade. Isto seria uma conseqüência da própria redução do tempo de trabalho socialmente necessário. Haveria uma regressão ao narcisismo primário, fase na qual o Ego e o mundo ainda não se distinguem (MARCUSE, 1999a, p. 152).

Sob um novo princípio de realidade, portanto, homem e natureza, razão e imaginação, não seriam mais incompatíveis entre si; Eros não seria mais inimigo da civilização, e sim o fundador de uma nova civilização. Nessa nova ordem não-repressiva, tornada possível pela liberação dos instintos e pela transformação de Eros, os indivíduos passariam a ser conduzidos de acordo com princípios autônomos, auto-determinados: a humanidade finalmente realizaria, então, o mais alto ideal do lluminismo, a conquista da maioridade (mündigkeit). Assim, a liberação dos instintos, para Marcuse, tem também um caráter de libertação política e social, uma vez que ela é 
- pressuposto de uma sociedade verdadeiramente livre e emancipada.

\section{Perspectivas atuais do pensamento de Marcuse}

Desde o falecimento de Marcuse, em 1979, o interesse pelo seu pensamento tem diminuído progressivamente. Diversas razões podem ser apontadas para explicar este desinteresse pelo pensamento marcuseano. Entre elas, destacamos duas que, em nosso entender, são as mais fundamentais: uma de ordem prática e outra de ordem teórica. No campo da prática, entendemos que o refluxo dos movimentos revolucionários com os quais sua obra dialogava, de alguma forma, fez arrefecer o interesse por suas idéias, consideradas por muitos, datadas em demasia ou até mesmo superadas pelas recentes e profundas mudanças econômicas, sociais e políticas. A outra, no campo teórico, - que talvez seja a mais relevante - foi o novo contexto histórico-filosófico das duas últimas décadas. Desde a década de 80 , o mundo teórico, tanto na filosofia quanto nas ciências humanas, foi caracterizado pela hegemonia do pensamento "pós-estruturalista" ou "pós-moderno", voltando seu interesse para autores como Lyotard, Foucault, Derrida e Baudrillard. Além disso, assistimos a um surto de interesse pelas correntes típicas da filosofia anglo-americana, como o neopragmatismo e a filosofia analítica. Mesmo Habermas, excelente promessa de continuação da terceira geração da Escola de Frankfurt, parece ter abandonado, na atualidade, os pressupostos básicos da "teoria crítica da sociedade", procurando nas vertentes teóricas anglo-americanas um caminho filosófico próprio. Marcuse não tem sido considerado nesses novos debates teóricos, principalmente os relativos ao pensamento moderno e pós-moderno. Segundo Kellner (MARCUSE, 1999b, "Prefácio", p. 17), isto ocorre porque:

Ao contrário de Adorno, Marcuse não previu os ataques pós-
modernos à razão e ao Iluminismo e sua dialética não era
"negativa". Em vez disso, Marcuse adotava o projeto de
reconstruir a razão e de postular alternativas utópicas à
sociedade existente - uma imaginação dialética que foi
relegada em uma era que rejeita o pensamento
revolucionário e visões grandiosas de libertação e
reconstrução social.

Entendemos ser importante a retomada da teoria crítica de Marcuse, na medida em que ela pode nos fornecer instrumentos conceituais que continuam a ser relevantes para a teoria social e a política contemporâneas. No campo específico da teoria da sociedade, Marcuse nos legou perspectivas filosóficas sobre as formas de dominação e de libertação, um método crítico de análise da sociedade contemporânea e apontou possibilidades utópicas de transformação 
social. Seu pensamento procura retomar e superar as lacunas do marxismo ortodoxo e da própria teoria crítica original. Além disso, representa uma análise teórica e prática extremamente fecunda, que se coloca como alternativa às correntes atualmente valorizadas da teoria pós-moderna. A concepção de emancipação de Marcuse, entendida como pleno desenvolvimento do indivíduo numa sociedade não-repressiva, diferencia sua obra e nos proporciona uma instância crítica sobre as formas de dominação presentes na sociedade contemporânea. Sua teoria crítica da sociedade se apresenta como extremamente útil na atual conjuntura de hegemonia do pensamento conservador. Em sua obra, Marcuse mostrou como a ciência, a tecnologia e a própria teoria possuem uma dimensão política e produziu um conjunto de análises ideológicas e políticas acerca de muitas tendências de dominação na sociedade e na cultura, nunca abdicando de lutar por suas idéias, não apenas no campo da teoria, mas também no campo da prática política. Como observa Habermas (apud BERNSTEIN, 1998, p. 67), Marcuse evitou cair no ceticismo absoluto, na pura negatividade, buscando sempre apontar alternativas teóricas e políticas para o futuro:

Embora, certamente, Marcuse não fosse um pensador afirmativo, ele foi não obstante o mais afirmativo entre aqueles que elogiavam a negatividade. Com ele, o pensamento negativo manteve a confiança dialética na negação determinada, no descobrimento de alternativas positivas. Marcuse, ao contrário de Adorno, não se limitou apenas a cercar o inefável; ele fez apelo a alternativas futuras.

Acreditamos que Marcuse ultrapassa as limitações de muitas correntes atuais da filosofia e da teoria social e que seu trabalho proporciona um ponto de vista mais crítico sobre as tendências teóricas e políticas contemporâneas. Em particular, ele promove articulações entre filosofia, teoria social e política, e crítica da cultura e da ideologia que enriquecem a nossa compreensão dos fenômenos que caracterizam o capitalismo global. Enquanto no âmbito acadêmico ainda persistem fortes divisões e especializações entre as diversas disciplinas, Marcuse - seguindo a tendência original da teoria crítica - fornece uma visão interdisciplinar que vincula a filosofia com análises concretas da sociedade, da política e da cultura do nosso tempo. Esta abordagem dialética assegura à filosofia uma importante função crítica nos discursos teóricos contemporâneos.

Mantendo sua fidelidade ao pensamento de Marx, Marcuse sempre se preocupou em analisar as novas condições da sociedade capitalista, ao mesmo tempo em que denunciava os descaminhos do "socialismo real". A filosofia e a teoria social contemporâneas podem extrair do pensamento de Marcuse importantes instrumentos para a análise das 
transformações do capitalismo e da emergência do "novo" sistema econômico e político global. Para Marcuse "teoria social é teoria histórica" (1982, p. 15), portanto, ela deve teorizar sobre os fenômenos mais significativos do presente e sobre as transformações pelas quais vem passando a formação social capitalista. No momento em que diversos teóricos pós-modernos partem do pressuposto de uma ruptura histórica e declaram, inclusive, o "fim" do marxismo e da economia política, em nosso entender eles falham na análise das mudanças econômicas, sociais e políticas que caracterizam o capitalismo em sua fase neoliberal ou global. Eles aumentam e radicalizam o fosso entre teoria e prática, pensamento e história, cultura e economia. Marcuse, ao contrário, sempre ressaltou a importância de analisar as diversas mudanças históricas do capitalismo e relacionar as transformações sociais e culturais às transformações econômicas.

Consideramos especialmente relevantes, para a atualidade, as análises de Marcuse sobre o papel da tecnologia como forma de controle social. O determinismo tecnológico embutido no discurso hegemônico da globalização é um dos recursos mais poderosos, na atualidade, para a aceitação ideológica da "irreversibilidade" do domínio mundial do capital. Outro aspecto central da obra de Marcuse que pode iluminar o presente é sua análise da fusão entre a economia, a política e a cultura na sociedade unidimensional. $O$ processo de globalização neoliberal em curso tem promovido, não apenas uma simples fusão, mas a subordinação da política e da cultura à economia, na medida em que tudo e todos têm que se submeter à ditadura do mercado como força suprema da vida em sociedade. O caráter totalitário das democracias liberais finalmente se explicita através de seu reducionismo econômico, isto é, do esvaziamento da dimensão política e da homogeneização cultural, promovendo a primazia do mercado nas relações sociais. A crítica da ideologia de Marcuse, por sua vez, é essencial para a denúncia e o combate ao domínio hegemônico das teorias pós-modernas que, ao fazerem a crítica radical da racionalidade moderna, não distinguem a razão instrumental da razão crítica e, dessa forma, colaboram para o ataque conservador ao único instrumento que pode permitir pensar a utopia e a emancipação. Enquanto algumas dessas tendências de pensamento, resvalando muitas vezes no irracionalismo, têm renunciado a uma análise crítica e política do sistema vigente, Marcuse sempre se esforçou por vincular sua teoria crítica da sociedade com os movimentos sociais e políticos que lutam contra as tendências totalitárias da sociedade capitalista. Dessa forma, acreditamos que o pensamento de Marcuse fornece instrumentos e estímulos fundamentais, tanto para a filosofia quanto para a teoria social e política contemporânea, em sua tarefa irrecusável de apontar alternativas históricas ao sistema econômico e social dominante. 


\section{Referências Bibliográficas}

BRONNER, S. E. Da teoria crítica e seus teóricos. Campinas, SP: Papirus, 1997.

HABERMAS, J. Psychic thermidor and the rebirth of rebellious subjectivity. In: BERNSTEIN, R. (Ed.). Habermas and Modernity. Cambridge: The MIT Press, 1985.

HORKHEIMER, M. Eclípse da razão. São Paulo: Centauro, 2000.

KURZ, R. O colapso da modernização: da derrocada do socialismo de caserna à crise da economia mundial. Rio de Janeiro: Paz e Terra, 1993.

LOUREIRO, I. (Org.). Herbert Marcuse: a grande recusa hoje. Petrópolis, RJ: Vozes, 1999.

MARCUSE, H. Contra-revolução e revolta. Rio de Janeiro: Zahar Editores, 1981.

A Ideologia da Sociedade Industrial: o homem unidimensional. Rio de Janeiro: Zahar, 1982. II, 1997.

Cultura e Sociedade. Rio de Janeiro: Paz e Terra, vols. I e

Eros e civilização: uma interpretação filosófica do pensamento de Freud. Rio de Janeiro: Editora LTC, 1999a.

- Tecnologia, guerra e fascismo. São Paulo: Fundação Editora da UNESP, 1999b.

ROUANET, S. P. Teoria crítica e psicanálise. Rio de Janeiro: Tempo Brasileiro, 1989.

WOLFF, R. P.; MOORE JR., B.; MARCUSE, H. Crítica da tolerância pura. Rio de Janeiro: Zahar Editores, 1970.

ZIZEK, S. Elogio da intolerância. Lisboa: Relógio D’Água, 2006.

\section{Endereço para correspondência}

Luiz Antonio da Silva Peixoto

Rua Dr. José Barbosa no 110 / apto. 301, Bairro São Mateus, CEP 36025-270, Juiz de Fora MG, Brasil

Endereço eletrônico: luiz-peixoto@oi.com.br

Recebido em: 15/03/2010

Aceito para publicação em: 19/04/2010

Acompanhamento do processo editorial: Ariane P. Ewald e Jorge Coelho Soares

\section{Notas}

* Doutor em Filosofia pela Universidade Federal do Rio de Janeiro - UFRJ; Professor Adjunto do Departamento de Filosofia da Universidade Federal de Juiz de Fora UFJF, Juiz de Fora, MG, Brasil

${ }^{1}$ Para uma análise mais recente da identidade estrutural entre os sistemas produtivos dos países socialistas e dos países capitalistas. Cf. Kurz, Robert, 0 
colapso da modernização: da derrocada do socialismo de caserna à crise da economia mundial, 1993.

${ }^{2}$ Segundo Stephen Bronner, apesar de seu apoio explícito ao movimento estudantil, Marcuse manteve uma posição bastante crítica frente a ele: "Marcuse desconfiava do populismo do movimento, de suas tendências irracionalistas, e não tinha muito o que fazer com o rock e a cultura popular. Sempre foi altamente crítico da 'libertação sexual' e rejeitava os que acreditavam na possibilidade de fundir a arte com a realidade tal como ela existe. Isso, segundo ele achava, só resultaria em 'barbárie no auge da civilização'. Ao contrário de muitos de seus ex-colegas do Instituto, porém, ele nunca retirou seu apoio ao movimento". Cf. Bronner, Stephen E. Da teoria crítica e seus teóricos, 1997, p. 306. 